\title{
Decisionismo Jurídico nos Trópicos: revisitando o jurista Carl Schmitt em Carl Schmitt e a Fundamentação do Direito de Ronaldo Porto Macedo Jr.
}

\author{
Ronaldo Tadeu de Souza \\ ronaldolais@yahoo.com.br \\ Mestre em Ciência Política pelo \\ Programa de Estudos Pós-Graduados \\ em Ciências Sociais da PUC-SP. \\ Graduado em Ciências Sociais pela \\ Pontifícia Universidade Católica de \\ Sáo Paulo - PUC-SP. Professor de \\ Sociologia do Direito e de Filosofia \\ no Centro Universitário-Fieo \\ Departamento de Direito Civil e \\ Departamento de Comércio Exterior
}

\section{Resumo}

O artigo-resenha busca apresentar os favor de um sistema legal mais próximo das pontos mais importantes do livro "Carl Schmitt e a Fundamentação do Direito" de Ronaldo Porto Macedo Jr. O enfoque da resenha será discutir a teoria do ordenamento concreto de Carl Schmitt e de como esta atenua o decisionismo jurídico (soberania estatal) do jurista alemão, em 


\title{
Juridic Decisionism in Tropics: revisiting the jurist Carl Schmitt through of the book "Carl Schmitt and the Grounding of Law" by Ronaldo Porto Macedo Jr.
}

\author{
Ronaldo Tadeu de Souza
}

\section{Abstract}

The article-review seek to show the points more important of book. "Carl Schmitt and the Grounding of the Law" by Ronaldo Porto Macedo $J r$. The focus of the review will be to discuss theory of concrete ordering of Carl Schmitt and like that, soften the juridic decisionismo (sovereign stateowned) of jurist germany, in favour a law system more next to of the concretes and humans societies.

Key words

Carl Schmitt, Juridic Decisionism, Juridic Institucionalism, Concrete Ordering. 


\section{Sumário}

\section{Introdução}

1 Carl Schmitt revisitado: dissociação contextual

2 Carl Schmitt pelas lentes de Maurice Hauriou: dissociação intelectual-formativo

3 A Teoria do Ordenamento Concreto: dissociação teórico-conceitual

Conclusão

Referências Bibliográficas 


\section{Introdução}

Carl Schmitt (1888-1985) não foi só um dos mais eminentes intelectuais de seu tempo, mais precisamente, das décadas de 20, 30 e 40 na Alemanha, como também esteve associado ao regime político que ali vigorou: o nacional-socialismo ou de maneira mais emblemática, o nazismo. Filósofo do direito, jurista e teórico da política de grande erudição e enciclopedismo, típico do mandarim alemão de então, a obra de Carl Schmitt e seu percurso intelectual ficaram eivados pela participação "direta" que teve no movimento nazista. Dissociar o seminal pensamento jurídico de Schmitt de sua atuação na construção do arcabouço legal do Estado alemão liderado por Hitler sempre foi exercício dos mais ingratos - para os que ousaram fazêlo. Com efeito, as teorias jurídica e política de Carl Schmitt sofreram o insucesso da tentativa de dissociação; donde, na maioria das vezes, ambas foram lidas como a defesa e justificação do governo hitlerista. O pensamento jurídico ocidental, e em termos gerais o direito, talvez tenha perdido precioso tempo ao não dedicar atenção a estudos mais detidos sobre a filosofia do direito de Carl Schmitt; pois o autor de Teologia Política, A Crise do Parlamentarismo, A Ditadura, Teoria da Constituição, O Conceito do Político e Sobre os Três Tipos de Pensamento Jurídico muito tinha e tem a dizer aos operadores do direito - advogados, promotores, juízes, ministro e teóricos do direito.

Ronaldo Porto Macedo Jr. busca, em seu Carl Schmitt e a Fundamentação do Direito Ed. Saraiva/GV, 2011, dissociar o pensamento jurídico schmittiano do homem político Carl Schmitt acossado pelas tensões sociais e políticas da Alemanha das décadas de 20 e 30. Assim, Ronaldo Porto Macedo Jr. tem como um de seus objetivos: recuperar o tempo perdido pela desconfiança a respeito da obra de Schmitt e dispensar análise das frutíferas contribuições para o direito das teorizações jurídicas do cidadão de Plettenberg.

Resultado de uma dissertação de mestrado defendida no departamento de filosofia da USP, sob orientação do professor e filósofo José de Arthur Giannotti, o livro ora publicado (republicado) pela Saraiva/GV está em sua $2^{a}$ edição; (a primeira veio a público em 2001 pela editora Max Limond). Isto posto, quais são os elementos do livro a serem destacados e que serão objeto de estudo do presente artigoresenha? Valendo-se da ideia de dissociação entre a filosofia do direito schmittiana e o "homem político" Carl Schmitt, podemos dizer que os pontos de força do livro de Ronaldo Porto Macedo Jr. sejam três: 1) dissociação contextual, na qual o autor aborda os motivos que conduziram Carl Schmitt a aderir a nacional-socialismo da década de 30 na Alemanha; 2) a dissociação intelectual-formativo, pois Ronaldo Porto Macedo Jr. analisa uma influência "oculta" na formação teórico-jurídico de Carl Schmitt, a do jurista francês Maurice Hauriou - frisemos que parte significativa 
dos estudiosos do jurista alemão, apresenta, sua obra como uma continuação linear das teorias políticas da soberania, Hobbes-Bodin-Weber e 3) a dissociação teóricoconceitual, aqui é onde irrompe no estudo de Porto Macedo Jr. a argumentação, demonstrando que Schmitt desloca o decisionismo puro, aberto e violento se se preferir, em favor da acurada e percuciente teoria-sistema do ordenamento concreto.

\section{Carl Schmitt revisitado: dissociação contextual.}

As análises correntes, convencionais, sobre o percurso intelectual de Carl Schmitt - com elementos justificáveis é verdade - suas concepções jurídicas, sua participação no governo alemão dos anos 30 , vale dizer, leem a filosofia do direito e a teoria política do cidadão de Plettenberg a partir da dinâmica cotidiana do Estado nacional-socialista alemão. E mais: analisam de maneira marginal a participação mesma de Carl Schmitt no governo hitlerista; as abordagens mais apresentam o quadro referencial histórico da época e deduzem pontos conectivos, bem como alguns conceitos que em forma de centelha surgem na obra de Schmitt, do que analisam o tipo e a característica da participação de Carl Schmitt no governo do Estado nazista. Ronaldo Porto Macedo Jr., neste aspecto, fornece aos estudiosos do jurista alemão análise seminal: um estudo detalhado da relação efetiva, porque é de relação que se deve falar e não simplesmente de participação, do jurista de Bonn não só com o governo nacional-socialista de 30, mas com as instituições constitutivas da estrutura de comando do movimento nazista e com os indivíduos e grupos que dirigiam e administravam estas instituições.

Com efeito; Ronaldo Porto Macedo Jr. diz que: "Em 1933, Schmitt ainda mantinha uma aversão conservadora ao nazismo"1 (grifo meu), ou seja, Macedo Jr. chama a atenção para a complexa atitude de Schmitt em relação ao governo hitlerista. Afirmar da adesão incondicional, direta, conscientemente convicta e até sanguinária de Carl Schmitt ao nazismo é para dizer no mínimo desconhecedor dos fatos capitais que o levaram à participação no movimento hitleriano. A dissociação contextual empreendida por Macedo Jr. em "Carl Schmitt e a Fundamentação do Direito" prossegue na compreensão que faz de duas circunstâncias importantíssimas da atitude de Schmitt no regime nacional-socialista. É, sobejamente conhecido, que o impulso simbólico do nazismo foi dado pelo ódio aos judeus e ao judaísmo - como fundamento de raça e sistema cultural. De modo que o programa de ideias do movimento nazista deu vida a teorias várias que, por um lado, negava qualquer valor significativo aos judeus e ao judaísmo; foi incutido na sociedade alemã em crise a

1 MACEDO JR., Ronaldo Porto. Carl Schmitt e a Fundamentação do Direito. São Paulo: Saraiva/GV, 2011, pag. 24. 
percepção da inferioridade racial-biológica da população judaica - daí a necessidade e justificativa para o extermínio em massa dos judeus; por outro lado, a convicção da superioridade da cultura alemã frente às outras culturas configurou-se na assertiva de que seria necessário para a Alemanha retomar seu lugar de destino na cultura ocidental e submeter qualquer outra comunidade de estirpe que se tornasse um obstáculo - e os judeus na leitura do habitus alemão ${ }^{2}$ era uma dessas comunidades. Quanto a isto o estudo de Macedo Jr., talvez pioneiro na universidade brasileira sobre este ponto, diz que:

Conforme bem observa Karl Löwith, Schmitt, em sua nova edição do Conceito do Político de 1933, eliminou sua referências a Marx e Lukács, de modo a tornar o texto mais aceitável aos nazistas. Schmitt inseriu, igualmente, observações antissemitas em suas obras. Vale notar, todavia, que, mesmo mencionando ideias de raça, sangue e identidade de estirpe, Schmitt jamais se filiou à teoria nazista oficial do racismo biológico. Tal posicionamento fixará um ponto de vulnerabilidade frente a seus opositores dentro do Partido Nacional-Socialista ... Em seus textos de cunho antissemita, em que ataca a inexpressividade da cultura jurídica judaica, Schmitt procura, provavelmente, evitar os seus embaraçosos envolvimentos com intelectuais judeus ocorridos no passado. Dentre os fatos mais significativos, basta lembrar sua amizade e admiração com relação a Walter Benjamin (de quem chegou a escrever uma resenha do livro A origem do drama barroco alemão), Hugo Preuss (sobre quem escreveu o livro Hugo Preuss Under Deutschen Staatlhere - Hugo Preuss na Teoria do Direito Alemão), Leo Strauss e Waldemar Gurian. ${ }^{3}$

Com isso, Ronaldo Porto Macedo Jr. penetra de fato na atitude de Carl Schmitt em relação ao nazismo e seu ideário antissemita: ambígua, contraditória, circunstancial e essencialmente oportunista é o que se pode dizer da participação de Schmitt no movimento nacional-socialista alemão de acordo com as analises de Macedo Jr. em Carl Schmitt e a Fundamentação do Direito.

Do ponto de vista das instituições do nazismo e de seus líderes, a abordagem sobre a participação de Carl Schmitt deve ser, também, matizada. É sobre o signo da matização, que Ronaldo Porto Macedo Jr. enfrenta a questão. O estudo das relações de eminentes intelectuais com Estados, regimes e governos ditatoriais, violentos e controversos como foram o nazismo alemão, o fascismo italiano, o stalinismo na União Soviética e o neoconservadorismo norte-americano são, invariavelmente, unilaterais; na medida em que a compreensão de dita participação focaliza, de modo

2 ELIAS, Norbert. Os Alemães: a luta pelo poder e a evolução do habitus nos séculos XIX e XX. Rio de Janeiro: Jorge Zahar, 1997.

3 MACEDO JR., Ronaldo Porto. Carl Schmitt e a Fundamentação do Direito. São Paulo: Saraiva/GV, 2011, pag. 25. 
exclusivo a aderência do intelectual em questão aos regimes e governos citados e outros. Escapa-lhes: como os Estados, regimes e governos citados, mais particularmente, as instituições e os líderes que os conformavam se relacionavam com os intelectuais que participaram direta e indiretamente de suas aventuras políticas - em nosso caso especifico Ronaldo Porto Macedo Jr. distingue, de passagem, o posicionamento do regime nazista em relação a Heidegger e Carl Schmitt. (Aquele, intelectual de "confiança" do nazismo; senão como compreender sua ascensão ao pináculo da hierarquia da universidade alemã naquele momento histórico, e ser incumbido do expurgo de diversos professores e intelectuais de importância acadêmica reconhecida). Assim, Macedo Jr. observa que: “... em 1934 Schmitt ainda gozava de prestígio junto à cúpula nazista e mantinha contatos frequentes com Goring, Hans Frank e outros membros do alto escalão como Goebbels, Hess, Himmler e Alfred Rosemberg", 4 mas entrementes,

Em fevereiro de 1934, Schmitt recebeu o primeiro ataque sério por parte de Otto Koellreuter, um dos advogados do racismo ideológico. Em outubro de 1934, o outrora discípulo de Schmitt, Gurian, sob o pseudônimo de Paul Miller, publicou um artigo no Schweizerischen Rundschaun denunciando as mudanças no pensamento de Schmitt e sua passagem do catolicismo para o nacional-socialismo. O texto mencionava os envolvimentos de Schmitt com intelectuais judeus e não arianos, como Moritz Julius Bonn e Hugo Preuss, alem de seu papel como intelectual de proeminência do pensamento católico conservador. $^{5}$

Com efeito, a adesão de Carl Schmitt, como bem demonstra o livro de Macedo Jr., foi muito mais de ocasião do que fundada em convicções sedimentadas ao longo do tempo.

Estes elementos de caráter biográfico-político, por si só já tornariam o livro de Ronaldo Porto Macedo Jr. em leitura obrigatória para os estudiosos da obra do jurista alemão, dadas as analises cuidadosas, inéditas e feitas com esmero; mas Macedo Jr. constrói um panorama teórico imprescindível para o entendimento do conjunto do pensamento jurídico-político de Carl Schmitt.

4 MACEDO JR., Ronaldo Porto. Carl Schmitt e a Fundamentação do Direito. São Paulo: Saraiva/GV, 2011, pag. 27.

5 MACEDO JR., Ronaldo Porto. Carl Schmitt e a Fundamentação do Direito. São Paulo: Saraiva/GV, 2011, pag. 27. 


\section{Carl Schmitt pelas lentes de Maurice Hauriou: dissociação intelectual-formativo.}

É ponto convergente, unanime por assim dizer, que as influências mais marcantes na filosofia do direito de Schmitt são a do filosofo político Thomas Hobbes e do sociólogo alemão Max Weber. Respectivamente, Carl Schmitt empresta destes autores: 1) a concepção soberana da política estatal, vale dizer, é a autoridade, sem réplica, do soberano que faz surgir os fundamentos da lei e 2) a crença de que uma comunidade nacional de valores deve ser conduzida pelo Estado, de modo a dominar (legitimamente) os agrupamentos políticos adversos no interior da nação (o monopólio da força física) e projetar-se com vigor e pujança no contexto internacional. Macedo Jr., no seu Carl Schmitt e a Fundamentação do Direito efetua uma desvio analítico - nos termos do presente artigo-resenha, efetua a dissociação intelectual-formativo. Assim, ao decisionismo hobbesiano-weberiano, Macedo Jr. agrega à filosofia jurídica schmittiana: a teoria institucional de Maurice Hauriou.

\footnotetext{
Para Hauriou, as instituições representam no direito a categoria da duração e continuidade do real ... O institucionalismo jurídico, para Hauriou, remete a duas questões básicas, a saber: 1) aquela necessária para estabelecer o grau de consenso que subsiste nas instituições e, desse modo, o fundamento de seu poder, em particular do soberano; e 2) o grau de sua objetividade, vale dizer, a medida de sua existência, questão que, por sua vez, remete à relação existente entre o objetivismo e o subjetivismo jurídico. O institucionalismo é uma tentativa de superar o confronto entre o objetivismo e o subjetivismo. Tal superação desdobra-se em importantes implicações quanto à teoria da soberania e seu relacionamento com a fundamentação do direito. ${ }^{6}$
}

A postulação por Hauriou de um institucionalismo jurídico, deve-se, ao diagnóstico feito pelo autor da volição estatal enquanto modulação, quase que exclusiva, do arcabouço jurídico das sociedades ocidentais - aqui, a sombra perturbadora da filosofia política moderna de Hobbes e Rousseau, Hegel e Kant, Max Weber e Jellinek é determinantemente fatal. Vale dizer: o reduzido espaço das instituições objetivas na construção dos sistemas jurídicos ocidentais é coberto pelo hipersubjetivismo estatal dos teóricos da vontade geral. Dessa forma, o direito torna-se um conjunto de normas e regulamentos atemporais - sem conexão com o solo real das relações sociais e humanas. Entretanto, de acordo com Hauriou o excesso de objetivismo torna a personalidade jurídica, sem valor. A solução seria a superação desta dicotomia rígida: subjetivismo jurídico versus objetivismo "institucional".

Seguindo a análise de Ronaldo Porto Macedo Jr., Hauriou avança dois tipos de

6 MACEDO JR., Ronaldo Porto. Carl Schmitt e a Fundamentação do Direito. São Paulo: Saraiva/GV, 2011, pag. 68. 
(novo) institucionalismo. A instituição-pessoa e a instituição-coisa são construções teóricas que propõem a reformulação da filosofia do direito enquanto fundamento subjetivista, hipersubjetivista na terminologia hiperbólica de Hauriou, e objetivista. Conforme a abordagem de Macedo Jr., a reformulação proposta por Hauriou da dicotomia rígida que fundamenta a filosofia do direito ocidental, possui a seguinte dinâmica: as instituições-pessoa que se corporificam nos diversos poderes comunitários organizados são a maneira em que os membros constitutivos destes poderes incorporam e interiorizam o valores e a cultura legal, i.e., as associações, sindicatos, partidos políticos e movimentos sociais são, assim, os elementos de equilíbrio e permanência do sistema jurídico, de modo que a mera volonté d'etat não é suficiente para a própria consolidação do direito; mas a instituição-coisa irrompe, disponibilizando para as instituições-pessoa a ambiência social externa, pois essa “... modalidade de instituição seria justamente a regra jurídica estabelecida socialmente ... é uma instituição porque ... vive no ambiente social ... [e] ... vive tanto no seio do corpo social como no Estado"' (grifo meu).

\section{A Teoria do Ordenamento Concreto: dissociação teórico-conceitual.}

É a leitura desta teoria do institucionalismo jurídico de Maurice Hauriou que permitirá Carl Schmitt preencher seu decisionismo estatal-legal volitivo (hobbesiano e weberiano por assim dizer), com instituições concretas do mundo social. O soberano - não é mais o que decide sobre o estado de exceção, mas o que consegue plasmar, na sociedade concreta, e para o bem-estar da própria sociedade concreta, a decisão legal. Este "achado" do livro de Ronaldo Porto Macedo Jr., o torna uma trilha intelectual obrigatória para os estudiosos do jurista alemão, bem com para os que se debruçam sobre os problemas atuais do sistema jurídico brasileiro e internacional. Chegamos dessa forma ao terceiro ponto de destaque do empreendimento teórico de Macedo Jr.; chamamos este ponto de dissociação teórico-conceitual. Para Ronaldo Porto Macedo Jr. a incorporação do arcabouço teórico da sociologia das instituições jurídicas de Hauriou permitiu, de maneira resoluta, a Carl Schmitt "rever" a teoria do decisionismo jurídico soberano e a criar a teoria do Konkretes Ordnungsdenken (pensamento do Ordenamento Concreto).

Em que consiste a teoria jurídica do ordenamento concreto de Carl Schmitt? Partindo de uma análise densa e sistemática de texto pouco conhecido de Schmitt; o texto é Sobre os Três Tipos de pensamento Jurídico, Macedo Jr. define assim o conceito de ordenamento concreto:

7 MACEDO JR., Ronaldo Porto. Carl Schmitt e a Fundamentação do Direito. São Paulo: Saraiva/GV, 2011, pag. 70. 
Para Schmitt, a decisão soberana nasce de uma decisão necessariamente arbitrária que instaura uma ordem na qual atuam as instituições. A decisão soberana instaura uma normalidade em substituição ao caos. O pensamento do ordenamento concreto de Schmitt combina instituição à decisão de maneira sincrética, coerente e sistemática. As instituições nascem de uma decisão arbitrária, mas ganham autonomia, formando-se uma 'vontade institucional'. As instituições, na medida em que são sedes de autoridade, criam valores e conteúdos, os quais, por sua vez, influenciarão, na própria formação do poder soberano ... Por fim, o Estado, enquanto 'Instituição das Instituições', une e subordina as demais instituições ... O decisionismo institucionalista schmittiano consiste nesse sistema de imbricação e dependência, que combina o elemento ocasional da decisão originária (a soberania ou da instituição) com a dinâmica de criação de valores e conteúdos do jogo institucional. ${ }^{8}$

A passagem é clara: ao seu decisionismo soberano-estatal (associado ao totalitarismo nazista) como criador do direito, Carl Schmitt funde uma vontade institucional dando origem ao ordenamento concreto.

\section{Conclusão}

O que Ronaldo Porto Macedo Jr. demonstra na obra do jurista alemão não é uma isenção ingênua de sua contribuição na organização do sistema jurídico do Estado hitleriano, mas sim, e esta é a grande contribuição de seu estudo, um artefato teórico inestimável para os operadores do direito da abordagem schmittiana concernente às instituições concretas e a relação que estabelecem com o Estado soberano - lei e normas vigentes criadas pelo soberano. Com efeito, a teoria do ordenamento concreto procura sedimentar nas sociedades humanas reais, os valores e juízos do sistema legal criado pelo soberano; ao fazer isto, ou vislumbrar fazê-lo, necessariamente deve lançar atenção, não para seu próprio ordenamento, mas para a dinâmica existencial das sociedades, instituições e indivíduos concretos - na nova filosofia do direito de Carl Schmitt, ao Estado legal soberano deve corresponder uma sociedade concreta legal. Se, no tempo de Schmitt não era pouco tal leitura, hoje, sem dúvida, menos ainda. Em uma sociedade humana concreta com complexidades e demandas varias - união homoafetiva, ecologia, família e drogas, violência juvenil, corrupção política, ineficiência do judiciário, mundo virtual e sua lógica operativa, sexo e pornografia - a leitura do livro do Professor Ronaldo porto Macedo Jr. Carl Schmitt e a Fundamentação do Direito torna-se, também, uma nova demanda para os profissionais do direito, e de outras ciências sociais.

8 MACEDO JR., Ronaldo Porto. Carl Schmitt e a Fundamentação do Direito. São Paulo: Saraiva/GV, 2011, pags. 104 e 105. 


\section{Referências Bibliograficas}

ELIAS, Norbert. Os Alemães: a luta pelo poder e a evolução do habitus nos séculos XIX e XX. Rio de Janeiro: Jorge Zahar, 1997.

MACEDO JR., Ronaldo Porto. Carl Schmitt e a Fundamentação do Direito. São Paulo: Saraiva/GV, 2011. 